\title{
CMEARTICLE
}

\section{Managing unhealthy alcohol use in general practice}

Sarah Shin Man $\underline{\mathrm{Lau}}^{1}$, MBChB, Sky Wei Chee $\underline{K o h^{2,3}}$, MBChB, MMed, Yit Shiang $\underline{\mathrm{Lui}}{ }^{4}$, MMed, MRCPsych

\begin{abstract}
Mr Tan, a 39-year-old banker, visited your clinic complaining of difficulties in falling asleep. This started six months ago after he underwent an acrimonious divorce, and he was desperate for a permanent solution to his insomnia. He admitted to drinking half to one bottle of red wine every night with his dinner to help him relax after a long and stressful day at work. He also enjoyed drinking 'a few' nips of whiskey when socialising with his friends, about two to three times a month. Recently, he missed a day of work after having had a drinking session the night before and his boss had given him a stern warning. He denied having any low mood or anhedonia. He went to see you to take medical leave, as he felt too tired to concentrate on his work that day.
\end{abstract}

\section{WHAT IS UNHEALTHY ALCOHOL USE?}

Unhealthy alcohol use is an umbrella term that encompasses a spectrum of behaviours, ranging from risky drinking to alcohol use disorder. ${ }^{(1)}$ Risky alcohol use is defined as: binge drinking, heavy drinking, or any alcohol use by pregnant women or those under 21 years of age. ${ }^{(2)}$ Alcohol use disorder is categorised by severity according to the number of criteria present (Fig. 1). ${ }^{(3)}$ Mild alcohol use disorder is broadly equivalent to alcohol abuse, while moderate and severe alcohol use disorder are broadly equivalent to alcohol dependence, as defined in the Diagnostic and Statistical Manual of Mental Disorders (Fourth Edition).

\section{Local recommendations}

In Singapore, the maximum recommended alcohol intake is two standard drinks per day for men and one standard drink per day for women. ${ }^{(4)}$ Definitions of a standard drink vary internationally. In Singapore, one standard drink is equivalent to $10 \mathrm{~g}$ of pure alcohol (Fig. 2) compared to $14 \mathrm{~g}$ in the United States. The United Kingdom defines one unit as $8 \mathrm{~g}$ of pure alcohol. ${ }^{(5}$

Another useful way of calculating alcohol intake is by using the following formula: ${ }^{(6)}$ number of standard drinks = amount of drink (in litres) $\times$ alcohol by volume $(\%) \times 0.789$ (density of ethanol at room temperature). For example, for a $500-\mathrm{mL}$ bottle of beer that is $5 \%$ alcohol by volume, the number of standard drinks it contains is: $0.5 \times 5 \times 0.789=1.97$ standard drinks.

\section{HOW COMMON IS THIS IN MY PRACTICE?}

According to the Singapore Mental Health Study 2016, 4.1\% and $0.5 \%$ of the population suffer from alcohol abuse and alcohol dependence, respectively, at some point in their lifetime. Those who were more likely to have alcohol use disorders were male, aged 18-34 years, of lower education attainment and employed. Among all people with a mental disorder who sought help, 20\% presented to a general practitioner.(7)

The prevalence of binge drinking, in particular, is a rapidly growing problem, with a prevalence of $13.7 \%$ in 2016 . Male and younger individuals (aged 18-34 years) were more likely to binge drink. ${ }^{\left({ }^{(8)}\right.}$ Underage drinking is also a problem, with a World Health Organization study from 2004 demonstrating that $73.5 \%$ of males and $64.5 \%$ of females aged $15-19$ years drank alcohol. ${ }^{(9)}$

\section{HOW RELEVANT IS THIS TO MY PRACTICE?}

Alcohol use disorders are some of the most stigmatised mental health disorders in Singapore and, as such, patients rarely seek help for their condition. ${ }^{(10)}$ Results from the Singapore Mental Health Study demonstrated that only $18.9 \%$ of people with alcohol use disorder had sought help in their lifetime. ${ }^{(11)}$ Another study demonstrated that persons with alcohol use disorder, in particular alcohol dependence, had the highest 12-month treatment gap of all mental health disorders, at $97.1 \%$. This is largely due to the individual's failure to perceive the need for treatment. ${ }^{(10)}$

This highlights the important role that primary care physicians have to play in identifying vulnerable persons at risk for alcohol use disorder. Epidemiological studies have demonstrated a strong association between unhealthy alcohol use and certain physical and medical conditions, such as hypertension, heartburn, gastric ulcers, anaemia, abnormal liver enzyme levels and chronic pain syndromes, as well as major depressive disorder, insomnia, and problems in social life or at work. ${ }^{(1,11)}$ Screening for alcohol use disorders in these groups of patients will aid detection and earlier treatment initiation at the primary care level.

${ }^{1}$ Department of Family Medicine, ${ }^{2}$ National University Polyclinics, National University Health System, ${ }^{3}$ Division of Family Medicine, Yong Loo Lin School of Medicine, National University of Singapore, ${ }^{4}$ Department of Psychological Medicine, National University Health System, Singapore

Correspondence: Dr Sarah Lau Shin Man, Resident, Family Medicine Residency Programme, Department of Family Medicine, National University Health System, 1E Kent Ridge Road, NUHS Tower Block, Level 9, Singapore 119228. sarah_lau@nuhs.edu.sg 


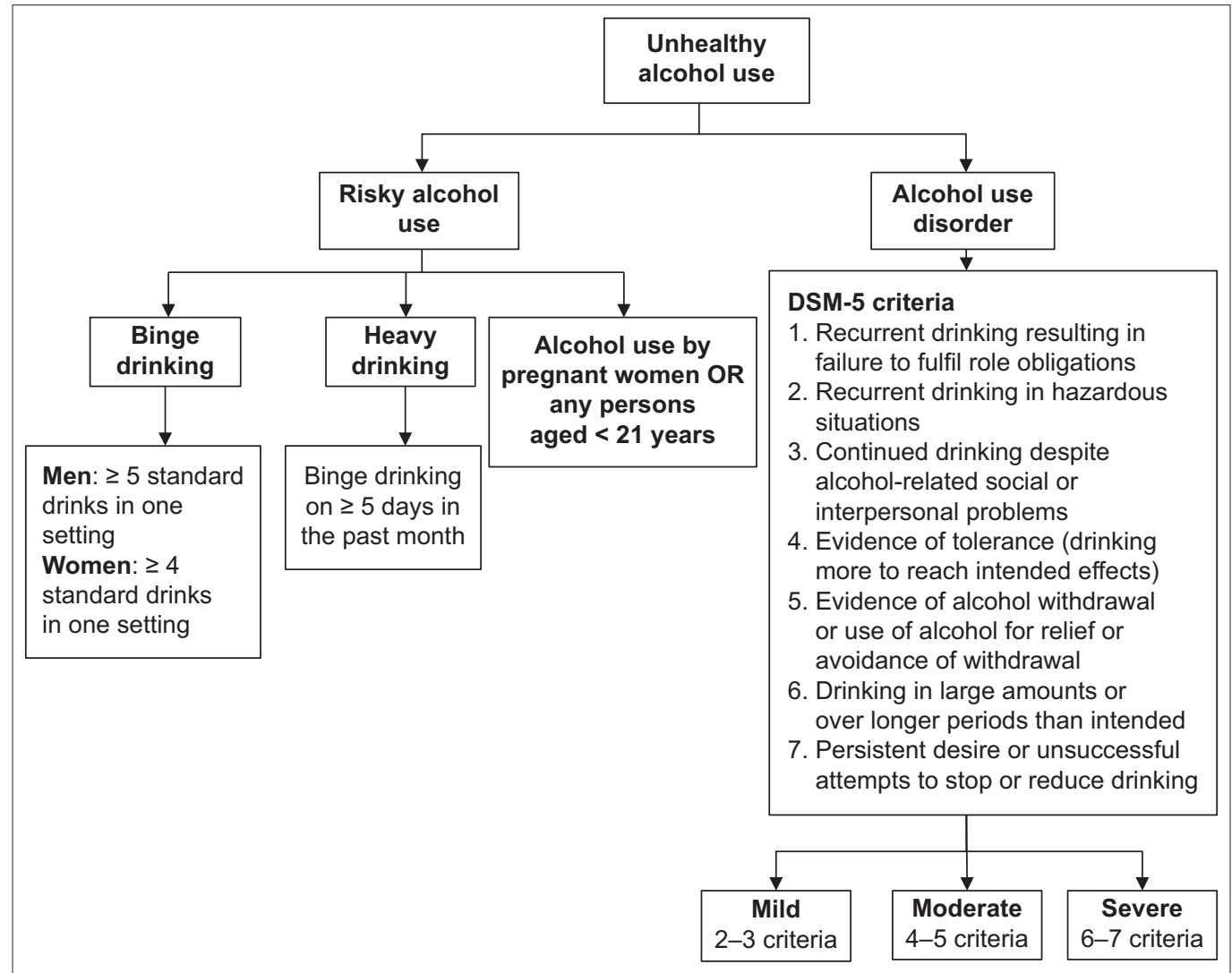

Fig. 1 Flowchart shows the definition of unhealthy alcohol use. ${ }^{(3)}$ DSM: Diagnostic and Statistical Manual of Mental Disorders

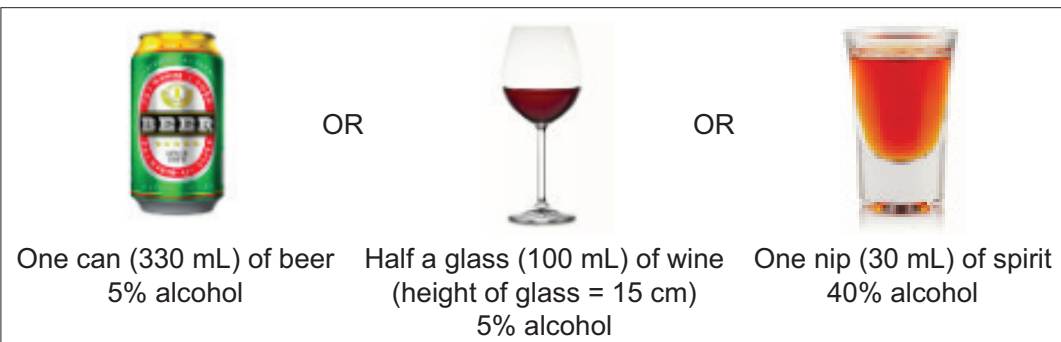

Fig. 2 Graphic shows examples of one standard drink in Singapore (10 g pure alcohol)

\section{WHAT CAN I DO IN MY PRACTICE? Screening}

Table I shows some screening tools that can be used in primary care. The most widely validated screening instrument is the tenitem Alcohol Use Disorders Identification Test (AUDIT), which was developed by the World Health Organization. ${ }^{(1)}$ The test provides greater specificity but takes longer to administer.

\section{Clinical history and physical examination}

Following a positive screening test, it is important to quantify alcohol use (Fig. 3). A useful tip is to empathetically ask in a non-judgemental way, "bring me through a typical day when you last drank". Allow the patient to describe the type and brand of alcohol and calculate his/her intake in terms of standard drinks. It is also important to evaluate the frequency of drinking, time of last drink, any binge drinking, and where and with whom they drink. Reasons for drinking, such as stress, low mood, family or relationship problems and peer pressure, should also be elicited.
It is important to acknowledge the significant impact of physicians' attitudes, knowledge and perception in eliciting this information. Open and non-judgemental attitudes are vital in encouraging patient disclosure.

A review of the patient's past medical history, along with a targeted systems review should be done to evaluate for physical and mental health complications of alcohol use disorder. Concurrent substance use, such as cigarettes and recreational drugs, should be screened for.

Clinicians should be mindful of alcohol withdrawal in higherrisk patients, which usually occurs after a drastic reduction in chronic alcohol drinking and within 6-24 hours of the last drink. Symptoms include anxiety, agitation, restlessness, tremors, insomnia, diaphoresis, palpitations, headache and alcohol craving. Patients may also experience nausea, vomiting and loss of appetite. Manifestations of severe withdrawal are hallucinations, seizures and delirium tremens. ${ }^{(14)} \mathrm{A}$ thorough physical examination, mental state examination and risk assessment should be performed. If 
Table I. Screening tools that can be used in primary care.

\begin{tabular}{|c|c|c|c|}
\hline Screening tool/question & Positive response & Advantage & Disadvantage \\
\hline $\begin{array}{l}\text { Single Alcohol Screening Question (SASQ) } \\
\text { How many times in the past year have you had } \geq 5 \text { (for men) or } \\
\geq 4 \text { (for women and all adults older than } 65 \text { years) drinks in a day? }\end{array}$ & $>0$ times $^{*}$ & $\begin{array}{l}\text {-Validated in primary care } \\
\text { - Easy and quick to use }\end{array}$ & $\begin{array}{l}\text { Does not provide } \\
\text { information on } \\
\text { drinking patterns }\end{array}$ \\
\hline $\begin{array}{l}\text { CAGE questionnaire }{ }^{(1)} \\
\text { 1. Have you ever felt you should Cut down on your drinking? } \\
\text { 2. Have people Annoyed you by criticising your drinking? } \\
\text { 3. Have you ever felt bad or Guilty about your drinking? } \\
\text { 4. Have you ever taken a drink first thing in the morning } \\
\text { (Eye-opener) to steady your nerves or get rid of a handover? }\end{array}$ & $\begin{array}{l}\geq 2 \text { affirmative } \\
\text { responses }\end{array}$ & $\begin{array}{l}\text { Easy to remember and } \\
\text { widely taught }\end{array}$ & $\begin{array}{l}\text { Does not assess } \\
\text { severity of alcohol } \\
\text { use disorders }\end{array}$ \\
\hline $\begin{array}{l}\text { AUDIT-C(13) } \\
\text { 1. How often do you have a drink containing alcohol? } \\
0=\text { never (i.e. } 0 \text { ) } ; 1=\text { monthly or less; } 2=2-4 \text { times a month; } \\
3=2-3 \text { times a week; } 4=\geq 4 \text { times a week } \\
\text { 2. How many drinks containing alcohol do you have on a } \\
\text { typical day? } \\
0=1-2 ; 1=3-4 ; 2=5-6 ; 3=7-9 ; 4=\geq 10 \\
\text { 3. How often do you have } \geq 6 \text { drinks (in men) OR } \geq 4 \text { drinks } \\
\text { (in women) on one occasion? } \\
0=\text { never; } 1=\text { less than once a month; } 2=\text { once a month; } \\
3=\text { once a week; } 4=\text { daily }\end{array}$ & $\begin{array}{l}\text { Women: } \geq 3 \\
\text { Men: } \geq 4^{+}\end{array}$ & $\begin{array}{l}\text { - Abbreviated version of } \\
\text { the AUDIT questionnaire, } \\
\text { which is the gold } \\
\text { standard screening } \\
\text { instrument for unhealthy } \\
\text { alcohol use } \\
\text { - Elicits a concise alcohol } \\
\text { history and gauges } \\
\text { severity: higher scores } \\
\text { are indicative of alcohol } \\
\text { dependence }\end{array}$ & $\begin{array}{l}\text { Takes longer to } \\
\text { administer }\end{array}$ \\
\hline
\end{tabular}

*SASQ score $>0$ is $82 \%$ sensitive and $79 \%$ specific for unhealthy alcohol use. + AUDIT-C score for alcohol dependence: women $\geq 3$ (73\% sensitivity, $91 \%$ specificity) and men $\geq 4$ ( $86 \%$ sensitivity, $89 \%$ specificity). AUDIT-C: Alcohol Use Disorders Identification Test-Concise

deemed necessary, a suicide risk assessment should be performed in those with severe psychiatric comorbidities.

\section{Special populations}

As there is no known safe level of alcohol consumption during pregnancy, alcohol should not be consumed in any quantity by pregnant women or women who are trying to get pregnant. Alcohol is teratogenic and also increases the risk of pregnancy loss. ${ }^{(1)}$ It is important to screen all pregnant women for alcohol consumption and counsel them appropriately.

\section{Laboratory investigations}

Investigations are useful to detect complications of alcohol use disorder. These include:

- $\quad$ Full blood count (to look for macrocytosis)

- Liver function tests (aspartate aminotransferase:alanine aminotransferase ratio of 2:1 suggests alcoholic liver disease)

- Gamma-glutamyl transferase (elevated in one-third of heavy drinkers)

- $\quad$ Electrocardiography

Carbohydrate-deficient transferrin is a more specific marker of chronic excessive alcohol use, although it is only available in specialist settings. In the inpatient setting, serum electrolytes (including sodium, potassium, magnesium and phosphate) should be checked, along with amylase, lipase and urine drug testing.

\section{Management: brief counselling and interventions}

We should educate all patients on their alcohol limits and advocate having at least 2-3 drink-free days per week. If any patient is contemplating reduction of his alcohol intake, motivational interviewing techniques can be used for brief intervention. For example:
Box 1. Alcohol and Singapore law:(15)

1. The legal drinking age is 18 years.

2. Anyone caught driving with a breath alcohol content $>30 \mathrm{mcg}$ alcohol in $100 \mathrm{~mL}$ of breath; or $>80 \mathrm{mg}$ of alcohol in $100 \mathrm{~mL}$ of blood can be charged with drink-driving. Persons can still be convicted of drink-driving if there is evidence that they cannot control the vehicle. If found guilty, persons can be liable for a maximum fine of SGD 10,000 and/or up to one year's jail.

3. The Liquor Control (Supply and Consumption) Act (2015) prohibits consumption of alcohol in public places and the sale of alcohol from retail outlets between $10.30 \mathrm{pm}$ and $7 \mathrm{am}$. Persons caught can face a fine of up to SGD 1,000 for a first-time offence, or up to SGD 2,000 and/or three months' jail for repeat offenders.

4. Geylang Serai and Little India are designated as Liquor Control Zones (LCZs) and have different restrictions. Alcohol cannot be consumed in public within LCZs during the following times: from 7 am on Saturdays to 7 am on Mondays; from $7 \mathrm{pm}$ on the eve of public holidays to $7 \mathrm{am}$ the day after the public holiday. Persons caught consuming alcohol in these areas will be liable for up to 1.5 times the penalty. Persons found to be drunk and incapable of taking care of themselves may be fined up to SGD 1,000 and/or jailed for up to one month.

5. Alcohol can be consumed within the privacy of your own home at any time of the day.

- $\quad$ "Would you like to hear more about what drinking does to you, and how to cut back?"

- "What have you tried before?"

- "What do you think are the good and not so good things about stopping drinking?"

To maintain rapport, efforts should be made to ensure continuity of care, with the same physician seeing the patient at all subsequent visits. Doctors should also keep up to date on the relevant laws related to alcohol use in Singapore (Box 1). ${ }^{(15)}$ 


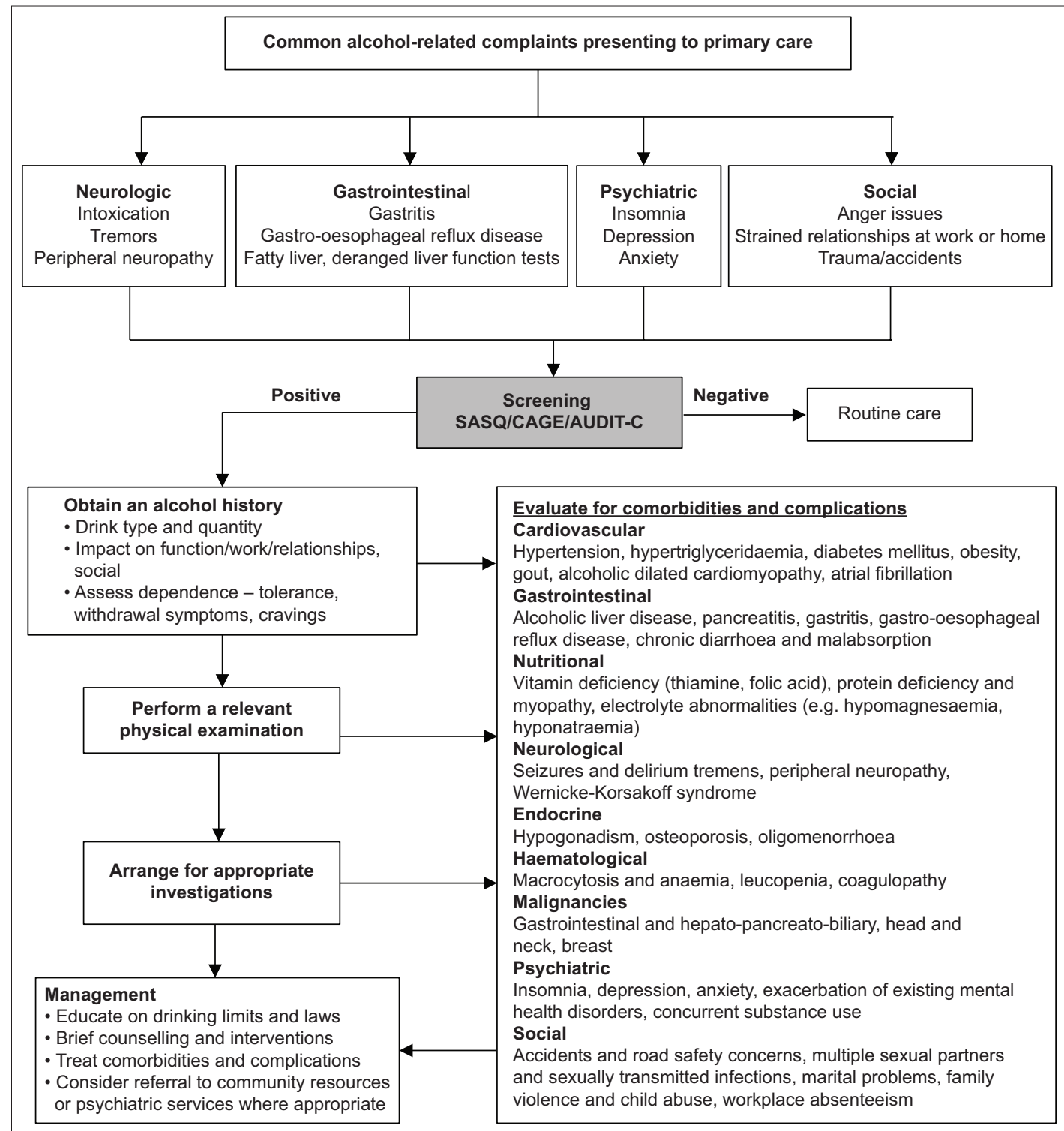

Fig. 3 Flowchart shows the approach to unhealthy alcohol use. AUDIT-C: Alcohol Use Disorders Identification Test-Concise; SASQ: Single Alcohol Screening Question

\section{WHEN SHOULD I REFER TO A SPECIALIST?}

Patients with mild alcohol use disorder can be safely managed in the community. Brief counselling and interventions, with close follow-up, may be sufficient for most of these patients. There are various resources that can provide further support for motivated individuals or those whose drinking is starting to affect their work or social lives (Table II). These are located in the community and within specialised centres at tertiary hospitals.

Patients with moderate to severe alcohol use disorder can be referred to specialist psychiatric clinics for consideration of medication-assisted detoxification therapy. Patients with concurrent psychiatric comorbidities and those with a history of recurrent failed detoxification attempts or delirium tremens should also be referred to specialist clinics. These are primarily based at the National Addictions Management Service (NAMS) within the Institute for Mental Health. NAMS also runs satellite Community Wellness Clinics at Geylang and Queenstown Polyclinics. There are also psychiatrists who run alcohol cessation services within National University Hospital and Changi General Hospital.
Patients with severe physical or psychiatric complications from alcohol use disorder should be referred to the emergency department for stabilisation. Those at high risk of harm to self or others and those with a lack of social support should also be referred for their safety.

\section{TAKE HOME MESSAGES}

1. Unhealthy alcohol use is a growing problem in Singapore, with the prevalence of alcohol use disorder and binge drinking steadily increasing in the last decade.

2. The recommended maximum alcohol intake is two standard drinks per day for men and one standard drink per day for women.

3. All at-risk adults should be screened for unhealthy alcohol use, using simple screening tools such as the Single Alcohol Screening Question, CAGE questionnaire or AUDIT-C.

4. Those who screen positive should undergo further assessment for alcohol use disorder, other substance abuse, and medical/psychiatric comorbidities and complications. 
Table II. Community resources and helplines.

\begin{tabular}{|c|c|}
\hline Community resource & Overview of services provided \\
\hline National Addictions Management Service (NAMS) & - Counselling services \\
\hline All Addictions Helpline: 6-RECOVER (6-7326837) & - Peer-support group meetings \\
\hline Email:nams@imh.com.sg & - Inpatient and outpatient detoxification programmes \\
\hline Website: http://www.nams.sg & - Complex case management \\
\hline Alcoholics Anonymous & - Counselling services \\
\hline Helpline: 64750890 & - Peer support group meetings \\
\hline \multicolumn{2}{|l|}{ Address: 1 Commonwealth Drive, Singapore 149603} \\
\hline \multicolumn{2}{|l|}{ Email: help@singaporeaa.org } \\
\hline \multicolumn{2}{|l|}{ Website: http://www.singaporeaa.org } \\
\hline WE CARE Community Services & - Counselling services, including individual, family and group therapy \\
\hline Helpline: 65475459 & - Educational and therapy programmes \\
\hline Email: help@wecare.org.sg & - Recovery support groups \\
\hline \multicolumn{2}{|l|}{ Website: www.wecare.org.sg } \\
\hline Al-Anon Singapore family groups & Supports families and friends of alcoholics \\
\hline \multicolumn{2}{|l|}{ Helpline: 98941201} \\
\hline \multicolumn{2}{|l|}{ Email: contactus@al-anonsingapore.org } \\
\hline Website: http://www.al-anonsingapore.org & \\
\hline
\end{tabular}

5. Laboratory investigations may be helpful as an adjunct to determine the severity of alcohol use disorder.

6. Primary care physicians have an important role in assessing risk and can also provide counselling and intervention. A therapeutic doctor-patient relationship can be fostered if efforts are made to ensure continuity of care.

7. Motivated individuals with alcohol use disorder can be referred to several community resources for more comprehensive management. Those assessed to be at higher risk for alcohol withdrawal syndromes should be referred to specialist psychiatric services for medication-assisted treatment.

You quickly found that Mr Tan screened positive on the Single Alcohol Screening Question. After further history-taking, you diagnosed him with mild alcohol use disorder. He had been using alcohol to cope with stress from work and his ongoing divorce proceedings. He had not realised that he had been drinking excessively until he met you and was open to accepting help. Apart from a borderline high blood pressure of 146/94 $\mathrm{mmHg}$, his physical examination was unremarkable. There were no features of alcohol withdrawal. He agreed to do basic laboratory investigations (full blood count, liver function tests and gamma-glutamyl transferase) and to return to see you next week to review his blood test results. In the meantime, he decided to sign up for the next Alcoholics Anonymous meeting to help him address his drinking problem.

\section{REFERENCES}

1. Saitz R. Unhealthy alcohol use. N Engl J Med 2005; 352:596-607.

2. Centers for Disease Control and Prevention. Advise about Risky Alcohol Use [online]. Available at: https://www.cdc.gov/ncbddd/fasd/features/reduce-riskyalcohol-use.html. Accessed September 27, 2020.

3. National Institute on Alcohol Abuse and Alcoholism. Alcohol Use Disorder: A Comparison Between DSM-IV and DSM-5 [online]. Available at: https://www. niaaa.nih.gov/publications/brochures-and-fact-sheets/alcohol-use-disordercomparison-between-dsm. Accessed September 27, 2020.

4. Ministry of Health Singapore. Alcohol and Health-Setting Your Drinking Limits [online]. Available at: https://www.healthhub.sg/live-healthy/920/alcohol-andhealth-set-your-drinking-limits. Accessed September 6, 2020.

5. International Organisation of Vine and Wine. Comparison of International Alcohol Drinking Guidelines [online]. Available at: https://www.oiv.int/public/ medias/7169/oiv-report-alcohol-drinking-guidelines-collective-expertise.pdf. Accessed January 25, 2021.

6. Health Promotion Agency, New Zealand. What's a standard drink? [online]. Available at: https://www.alcohol.org.nz/help-advice/standard-drinks/whats-astandard-drink. Accessed January 26, 2021.

7. Subramaniam M, Abdin E, Vaingankar JA, et al. Tracking the mental health of a nation: prevalence and correlates of mental disorders in the second Singapore mental health study. Epidemiol Psych Sci 2019; 29:e29.

8. Lee $\mathrm{YY}, \mathrm{W}$ ang PZ, Abdin E, et al. Prevalence of binge drinking and its association with mental health conditions and quality of life in Singapore. Addit Behav 2019; 100:106114.

9. World Health Organization. In: WHO Global Status Report on Alcohol 2004 [online]. Available at: https://www.who.int/substance_abuse/publications/ global_status_report_2004_overview.pdf. Accessed January 25, 2021.

10. Subramaniam M, Abdin E, Vaingankar JA, et al. Minding the treatment gap: results of the Singapore Mental Health Study. Soc Psychiatry Psychiatr Epidemiol 2020; 55:1415-24.

11. Subramaniam M, Abdin E, Vaingankar JA, et al. Prevalence and correlates of alcohol use disorders in the Singapore Mental Health Survey. Addiction 2012; 107:1443-52.

12. Smith PC, Schmidt SM, Allensworth-Davies D, Saitz R. Primary care validation of a single-question alcohol screening test. J Gen Intern Med 2009; 24:783-8.

13. Bradley KA, DeBenedetti AF, Volk RJ, et al. AUDIT-C as a brief screen for alcohol misuse in primary care. Alcohol Clin Exp Res 2007; 31:1208-17.

14. Turner RC, Lichstein PR, Peden JG, Busher JT, Waivers LE. Alcohol withdrawal syndromes: a review of pathophysiology, clinical presentation, and treatment. J Gen Intern Med 1989; 4:432-44.

15. Singapore Legal Advice. Legal drinking age in Singapore and other drinkingrelated laws. In: SG Legal Learning Centre [online]. Available at: https:// singaporelegaladvice.com/law-articles/legal-drinking-age-singapore-drinkingrelated-laws. Accessed September 6, 2020 


\section{SINGAPORE MEDICAL COUNCIL CATEGORY 3B CME PROGRAMME} (Code SMJ 202102A)

1. Features of alcohol use disorder include developing increasing tolerance and withdrawal symptoms from alcohol.

2. Worldwide, one standard drink is equivalent to $10 \mathrm{~g}$ of pure alcohol.

3. In Singapore, one standard drink is equivalent to a $330-\mathrm{mL}$ can of beer.

4. The maximum recommended alcohol intake in Singapore is two standard drinks per day for men and one standard drink per day for women.

5. Drinking three or more standard drinks in one night constitutes binge drinking.

6. A 42-mL shot of $30 \%$ alcohol-by-volume vodka is approximately equal to one standard drink.

7. In Singapore, $4.1 \%$ suffer from alcohol abuse at some point in their lives.

8. Alcohol use disorder can surface during chronic disease management consultations, in the form of deranged liver function tests, hypertriglyceridaemia, gout flares and hypertension.

9. The Single Alcohol Screening Question is a quick and useful tool to detect unhealthy alcohol use.

10. The CAGE questionnaire gives physicians adequate information to assess the severity of alcohol use.

11. History-taking and examination in patients with alcohol use disorder involve assessing for withdrawal, tolerance, functional limitation, and medical and psychiatric complications of alcohol use.

12. Investigations such as full blood count, liver function tests and electrocardiography are required to make the diagnosis of alcohol use disorder.

13. If the patient is keen to quit drinking, motivational interviewing techniques can be applied for brief intervention.

14. Persons below the legal breath alcohol limits can still be convicted for drink-driving if they cannot control their vehicle.

15. Alcohol can still be purchased from retail outlets at $11 \mathrm{pm}$ as long as you do not drink it in public.

16. Alcohol can be consumed within the Liquor Control Zones on Sunday evenings.

17. Alcohol use disorder cannot be managed in primary care.

18. Patients with concurrent psychiatric comorbidities, history of recurrent failed detoxification attempts or delirium tremens should be referred to specialist clinics.

19. After consuming alcohol, patients who are at risk to themselves or others can be referred to the emergency department for safety.

20. Alcoholics Anonymous and WE CARE are community resources for patients who are keen to seek help for their alcohol use.

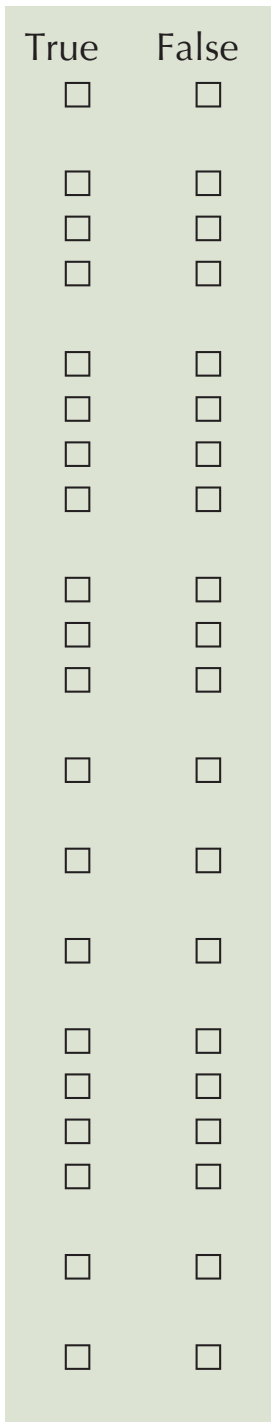

\section{Doctor's particulars:}

Name in full:

MCR no.:

Specialty:

Email:

\section{SUBMISSION INSTRUCTIONS:}

Visit the SMJ website: http://www.smj.org.sg/current-issue and select the appropriate quiz. You will be redirected to the SMA login page.

For SMA member: (1) Log in with your username and password (if you do not know your password, please click on 'Forgot your password?'). (2) Select your answers for each quiz and click 'Submit'.

For non-SMA member: (1) Create an SMJ CME account, or log in with your SMJ CME username and password (for returning users). (2) Make payment of SGD 21.40 (inclusive of $7 \%$ GST) via PayPal to access this month's quizzes. (3) Select your answers for each quiz and click 'Submit'.

RESULTS:

(1) Answers will be published online in the SMJ April 2021 issue. (2) The MCR numbers of successful candidates will be posted online at the SMJ website by 10 April 2021. (3) Passing mark is $60 \%$. No mark will be deducted for incorrect answers. (4) The SMJ editorial office will submit the list of successful candidates to the Singapore Medical Council. (5) One CME point is awarded for successful candidates. (6) SMC credits CME points according to the month of publication of the CME article (i.e. points awarded for a quiz published in the February 2021 issue will be credited for the month of February 2021, even if the deadline is in April 2021).

Deadline for submission (February 2021 SMJ 3B CME programme): 12 noon, 3 April 2021. 